\title{
露天爆破安全管理工作的探讨
}

奕辉 熊宏启 范晓明 崔志平

鞍钢集团鞍千矿业有限责任公司

DOI:10.18686/gmsm.v1i2.31

[摘 要] 在矿山开采工作中, 经常会涉及到露天爆破技术, 由于露天爆破工作具有一定的特殊性, 在实践的过程中危险系数 较高,在此情况下,强化对露天爆破的安全管理工作很有必要,本文主要针对这一问题展开了探讨和分析。

[关键词] 露天爆破; 安全管理工作; 探讨

随着社会经济的不断发展, 各行各业发展对于矿产资源 的需求量不断增加, 从而也对矿产资源开采规模提出更高要 求。此外, 在露天爆破环节中, 经常会出现很多安全事故, 威 胁着施工人员的生命安全, 为此, 强化对露天爆破的安全管 理工作很有必要。

\section{1 露天爆破安全管理工作现状分析}

首先, 在当前的矿山露天爆破安全管理工作团队中, 基 本上都以工作经验丰富的老员工为主, 在团队工作中得心应 手, 但由于这些人员的受教育水平普遍偏低, 对于新事物的 接受能力较差, 不能将一些现代化先进的科学技术融入于管 理工作中, 通常都是依据经验来行事, 缺乏发展观念和前瞻 性, 从而也对安全管理工作质量产生了直接影响。个别管理 人员还会排斥新技术和新观念, 并认为其不切实际, 过分的 安于现状, 十分不利于现有管理工作的改进与创新。

其次, 新加入的安全管理人员, 其受教育水平普遍偏高, 且接收过系统、正规的专业培训, 同时也拥有良好的知识接 受能力和职业素养。但在具体工作过程中, 却经常会因为工 作经验不足而无法胜任当前工作, 缺乏处理突发事件的能 力。在露天爆破安全管理方面, 不仅仅需要专业的理论知识, 同时也要求其具备良好的现场操控能力和人际关系处理能 力, 否则便会对工作质量产生直接影响。作为现场安全管理 人员, 应具备较强的现场管理能力, 要能够及时、精准的找到 施工人员的错误行为, 并进行制止, 如此才能从根本上提升 露天爆破安全管理工作质量 ${ }^{[1]}$ 。

最后, 由于企业对于露天爆破安全管理工作的重视程度 较低, 因此, 很难实现对管理人员的优化配置。还有很多工程 由于是新开工, 故根本无法在短时间内找到合适的、专业的 现场安全管理人员, 在此情况下, 经常为了应急而临时安排 一些非专业人员, 而这些人员未接受过正规、系统的教育与 培训, 因此, 根本无法胜任当前复杂多变的岗位工作, 安全管 理意识薄弱, 从而也导致安全管理质量大打折扣。

\section{2 提升露天爆破安全管理工作质量的有效建议}

2.1 完善安全保障体系

在进行露天爆破的过程中, 建立完善可行的安全保障体 系很有必要, 同时也能为爆破工作的顺利开展奠定良好基 础。正常情况下, 露天爆破安全保障体系可被分为技术保证、
人员保证和制度保证等等, 通过各项保证的顺利实施和运行, 可大幅度提升露天爆破安全管理工作质量。因此,一定要提 升对安全保障体系建设工作的重视程度, 通过动态化、先进 的管理模式, 真正做到发现问题及时解决, 以促进安全管理 工作的不断发展与完善, 为施工现场人员的生命安全提供保 障 $^{[2]}$ 。

2.2 结合爆破类型进行针对性的安全管理

在矿山开采工作中, 受到施工方式、地形等因素的影响, 经常会产生不同的采空区域, 由于这些区域的特性不同, 因 此, 在露天爆破的过程中, 必须要结合其实际特点开展针对 性的安全管理工作。

2.2.1 妥善做好火区和空巷区数据管理工作

在日常发展中, 安全管理人员要对火区和空巷区的动态 数据进行时刻关注, 必要时可进行追踪管理。在安全管理工 作中, 对于火区和空巷区的异常状况进行及时记录, 如此可 为后续的露天爆破工作提供价值参考和依据, 同时也为安全 管理工作的顺利开展提供了良好保障 ${ }^{[3]}$ 。

2.2.2 空巷区钻孔安全管理工作

空巷区在开展露天爆破工作的过程中, 由于区域宽度较 小, 因此在钻孔环节中经常会产生穿透的现象, 若现场工作 人员不进行及时检查, 便很难发现上述现象, 从而产生露天 炸药过量的问题, 影响爆破效果。在上述情况下, 由于碎石飞 贼, 还极易造成人员伤亡情况, 危险系数较高。鉴于此, 可在 今后的安全管理工作中, 适当扩大露天爆警戒范围, 以免产 生设备和人员损伤的情况。

\section{2 .3 妥善做好火区高温孔动态管理工作}

在露天爆破安全施工中, 妥善做好火区高温孔动态管理 工作很有必要, 实践过程中, 相关人员应严格按照要求对孔 内温度进行追踪和测量, 同时对孔内的热量头进行记录。在 开展降温工作的过程中, 也要及时记录好温度变化, 在完成 钻孔的降温处理工作后, 才能继续进行露天爆破 ${ }^{[4]}$ 。

\section{2.4 高效完成火区和空巷区封堵工作}

在完成穿孔之后, 个别钻孔极易产生温度升高和冒烟的 问题, 若在此过程中涌出大量的毒害气体, 便很可能导致钻 孔贯通问题, 使空气进入到空巷区域, 从而加大了火区的燃 烧范围和程度。为避免上述情况, 必须要妥善做好火区和空 
巷区封堵工作。

露天爆破在完成了钻孔之后还需进行一定的测量, 在完 成防线工作之后才能继续进行后续工作。边坡测量工作一般 包括两个方面: 第一, 对定位钻机操作平台进行测量; 第二, 通过全站仪, 对边坡定位进行二次测量, 每相隔 $10 \mathrm{~cm}$ 设置一 个边桩点 ${ }^{[5]}$ 。

在装药环节中, 要求施工人员严格按照规范来进行, 做 好药串、药包的加工, 保证各环节符合要求。对于缓冲孔, 一般可采用间隔装药的方式, 对于主爆孔可采用耦合装药的 方式。在加工环节, 可在竹片上绑扎导爆索炸药, 药串就位之 后, 选用松软物品进行遮挡 ${ }^{[6]}$ 。

\subsection{5 强化对人员的思想教育与培训}

在安全管理工作中, 科学的教育理念必不可少, 因此, 必 须要强化对安全管理人员的思想教育, 使其对安全管理工作 形成正确的认识。实践过程中, 要对员工的陈旧观念和错误 思想进行深入分析, 并加以引导和提示, 鼓励老员工积极接 收新思想和新技术。与此同时, 针对于老员工的思想教育工 作, 必须要进行辩证看待, 重视挖掘有价值的实践经验, 同时 还可定期开展一些经验讲座、“老带新” 等活动, 使老员工能 够将个人经验无私的贡献出来, 提升新员工实践经验, 丰富 其阅历。此外, 还可适当提升安全管理人员的薪资, 以提升其 工作积极性, 实现人员的优化配置, 从而为安全管理工作质 量的提升奠定良好基础。

\section{2.6 加大对各种新技术的应用力度}

若想提升安全管理工作质量, 必须要建立完善可行的培 训系统, 在员工上岗之前, 相关部门必须要对员工进行安全 教育与培训, 严格执行考核制度, 在考核通过之后颁发相关 证明。对于关键性岗位的人员, 需要求其持证上岗, 确保安全 管理培训工作能够落到实处。关于新员工的培训工作, 还应 立足于工作人员的实际情况, 重视教育培训效果的提升, 如 此才能为安全管理工作质量的提升奠定良好基础 ${ }^{[7]}$ 。与此同 时, 还可对各种现代化先进的露天爆破技术进行应用, 通过 全新理念的融入来武装安全管理人员的大脑。

\section{2 .7 优化企业露天爆破工作计划}

露天爆破安全管理工作具有一定的特殊性, 但从目前
实际发展情况上来看, 由于个别企业经常会过分注重经济 效益, 从而忽视了安全管理工作的重要性。对于上述企业, 其在今后发展过程中, 必须要积极转变思想观念, 对露天爆 破工作设计进行全面优化, 提升对安全管理工作的重视程 度。此外, 若想提升安全管理质量, 还要求安全管理人员具 备较强的沟通能力和专业素养, 要能够独立、出色的完成的 日常安全管理工作。实践过程中, 还可对国外先进管理经验 进行借鉴, 强化对各种先进技术和理论的应用, 但应注意不 可直接的照抄照搬, 而是要结合实际情况进行调整, 这样才 能为企业露天爆破工作的顺利开展提供保障, 提升工作安 全性。

\section{3 结语}

综上所述, 本文主要对露天爆破安全管理工作现状进行 了简要分析, 同时提出提升露天爆破安全管理工作质量的有 效建议。露天爆破工作具有一定的复杂性和综合性, 且危险 系数相对较高, 鉴于上述情况, 企业必须要提升对施工现场 管理工作的重视程度, 立足于企业发展实际, 提升安全管理 人员的综合素养和实践能力, 使其更好的胜任当前的本职工 作, 提高露天爆破安全管理工作质量, 为职工的生命安全提 供保障。

\section{[参考文献]}

[1]陈富强. 现场混装炸药车在露天爆破作业中的安全 管理[J].城市建设理论研究(电子版),2014,(6):2574-2575.

[2]刘占中.露天矿山爆破安全问题与防治措施探讨 [J]. 中国新技术新产品,2013,(9):346-317.

[3]彭生.关于露天爆破施工现场安全管理工作的几点体 会[J].科技创新与应用,2017,(8):149.

[4]关震.露天矿山爆破效果对开采成本的影响研究 [J]. 城市建设理论研究:电子版,2016,6(8):1344.

[5]徐敏.现场混装炸药车在露天爆破作业中的安全管理 [J].城市建设理论研究(电子版),2015,(16):2574.

[6]任建国.试述爆破安全技术在露天采掘施工中的应用 [J].城市建设理论研究(电子版),2015,(35):2612.

[7]贾思源,石坚.复杂环境条件下露天深孔爆破安全监理管 理实践[J]. 商品与质量・建筑与发展,2014,(8):689-682. 